\title{
RECENT ADVANCES IN SODIUM INTERCALATION POSITIVE ELECTRODE MATERIALS FOR SODIUM ION BATTERIES
}

\author{
JING XU, DAE HOE LEE and YING SHIRLEY MENG* \\ Department of NanoEngineering \\ University of California San Diego \\ 9500 Gilman Drive, La Jolla, CA 92093, USA \\ *shirleymeng@ucsd.edu
}

Received 10 January 2013; Accepted 30 January 2013; Published 14 March 2013

\begin{abstract}
Significant progress has been achieved in the research on sodium intercalation compounds as positive electrode materials for Na-ion batteries. This paper presents an overview of the breakthroughs in the past decade for developing high energy and high power cathode materials. Two major classes, layered oxides and polyanion compounds, are covered. Their electrochemical performance and the related crystal structure, solid state physics and chemistry are summarized and compared.

Keywords: Sodium-ion battery; cathodes; intercalation; review.
\end{abstract}

\section{Introduction}

The pressing needs for better energy storage technologies in large-scale applications that are economically feasible, particularly for the deployment of renewable energy sources, are strong drivers for fundamental research in new materials discovery and their electrochemistry. Li-ion batteries offer the highest energy density among all secondary battery technologies, have dominated the portable electronics market and have been chosen to power the next generation of electric vehicles and plug-in electric vehicles. Nevertheless, the concerns regarding the size of the lithium reserves and the cost associated with Li-ion technology have driven the researchers to search more sustainable alternative energy storage solutions. In this light, sodium-based intercalation compounds have made a major comeback because of the natural abundance of sodium.

It is important to point out that sodium based systems would have lower energy density in comparison to lithium based systems because of its intrinsic lower operation voltages. Typical energy densities range from $300-700 \mathrm{Wh} / \mathrm{kg}$ as shown in Fig. 1. On the other hand, the lower voltages would result in better safety and the possibility of using cheaper water based electrolytes. ${ }^{1}$ A more encouraging fact is that the Na-ion diffusion barriers in solid state compounds are comparable to the Li counterparts, indicating that $\mathrm{Na}$-ion systems can be competitive with Li-ion systems in terms of discharge/charge rates. Even though the ionic radii of Na-ion is considerably larger than that of Li-ion, more open structures can be made to accommodate large $\mathrm{Na}$-ions and allow fast solid state Na-ion diffusion at room temperature. ${ }^{2,3}$

In this letter, we review the major advances made in the past decade on sodium intercalation compounds as the positive electrode materials in Na-ion batteries. We will focus on the fundamental materials science aspects of two major classes of compounds: layered compounds and polyanion compounds. They have been extensively studied in recent years since their open structures can accommodate large $\mathrm{Na}$-ions and provide spacious diffusion path as well as the structural stability. The structure, phase stability and electrochemistry relations are discussed.

\section{Layered Oxide Compounds}

It is no wonder that sodium layered oxide compounds $\left(\mathrm{Na}_{\mathrm{x}} \mathrm{MO}_{2}\right)$ have drawn significant attention as cathode materials in Na-ion batteries considering that their $\mathrm{Li}$ analogues have been comprehensively understood for last two decades. The layered $\mathrm{Na}_{\mathrm{x}} \mathrm{MO}_{2}$ materials can be categorized into two major groups which are $\mathrm{P} 2$ and $\mathrm{O} 3$ type (Figs. 2(a) and 2(b)). The first letter "P" or "O" refers to the nature of the site occupied by alkali ion (prismatic or octahedral), and "2" or "3" refers to the number of transition metal layers in the repeat unit perpendicular to the layering. ${ }^{4}$ The structural properties of $\mathrm{Na}_{\mathrm{x}} \mathrm{MO}_{2}$ have been studied in 70's by Delmas et al., 5,6 and $\mathrm{Na}_{\mathrm{x}} \mathrm{CoO}_{2}$ has been revealed to show reversible phase transformations by electrochemical charge 


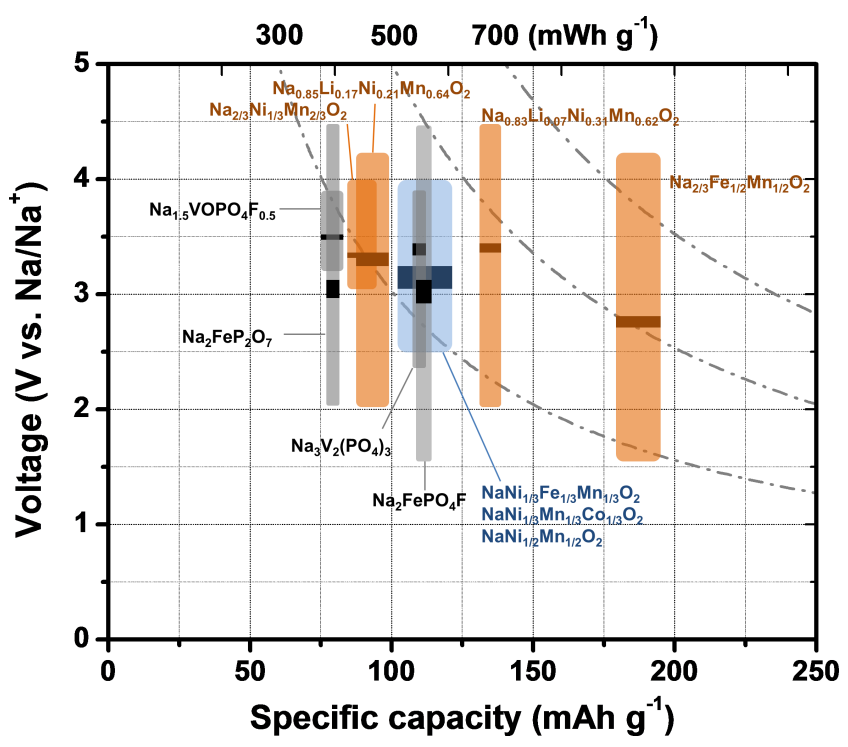

Fig. 1. A summary of specific capacity, operating voltage range and energy density of the intercalation cathode materials for Na-ion batteries (Center bar indicates average voltage).

and discharge demonstrating the feasibility of $\mathrm{Na}_{\mathrm{x}} \mathrm{MO}_{2}$ as a cathode material. ${ }^{7}$ However, limited efforts have been spent on Na-ion batteries during the past two decades due to the tremendous success of Li-ion batteries. Several studies on P2 or $\mathrm{O} 3$ type $\mathrm{Na}_{\mathrm{x}} \mathrm{CrO}_{2},{ }^{8} \mathrm{Na}_{\mathrm{x}} \mathrm{MnO}_{2},{ }^{9}$ and $\mathrm{Na}_{\mathrm{x}} \mathrm{FeO}_{2}{ }^{10}$ have been conducted in early $80 \mathrm{~s}$ to $90 \mathrm{~s}$, but the researches were limited to the structural studies up to $3.5 \mathrm{~V}$ vs. sodium upon the $1 \mathrm{st}$ cycle mostly due to the instability of the electrolyte.

Recent studies on $\mathrm{O} 3-\mathrm{Na}_{\mathrm{x}} \mathrm{MO}_{2}$ compounds started to reveal the fact that they can be utilized as a cathode electrode with excellent electrochemical properties in Na-ion cells. $\mathrm{NaCrO}_{2}$ was investigated by Komaba et al. and showed $120 \mathrm{mAh}^{-1}$ of specific capacity near $2.9 \mathrm{~V}^{11,12}$ Interestingly, $\mathrm{NaCrO}_{2}$ exhibited better electrochemical performances over that of $\mathrm{LiCrO}_{2}$ due to larger $\mathrm{CrO}_{2}$ inter-slab distance in $\mathrm{Na}$ compound. The $\mathrm{O} 3-\mathrm{NaNi}_{0.5} \mathrm{Mn}_{0.5} \mathrm{O}_{2}$ electrodes delivered $105 \mathrm{mAh} \mathrm{g}^{-1}$ at $1 \mathrm{C}\left(240 \mathrm{mAg}^{-1}\right)$ and $125 \mathrm{mAh} \mathrm{g}^{-1}$ at $\mathrm{C} / 30$ $\left(8 \mathrm{~mA} \mathrm{~g}^{-1}\right)$ in the voltage range of $2.2-3.8 \mathrm{~V}$ and displayed $75 \%$ of the capacity after 50 cycles. ${ }^{12,13}$ The $\mathrm{O} 3$ phase transformed into $\mathrm{O}^{\prime} 3, \mathrm{P} 3, \mathrm{P}^{\prime} 3$ and $\mathrm{P}^{\prime \prime} 3$ phases during the extraction of Na-ions (Fig. 3(a)). The Fe-substituted O3$\mathrm{Na}\left[\mathrm{Ni}_{1 / 3} \mathrm{Fe}_{1 / 3} \mathrm{Mn}_{1 / 3}\right] \mathrm{O}_{2}$ exhibited the specific capacity of $100 \mathrm{mAh}^{-1}$ (avg. V: $2.75 \mathrm{~V}$ ) with smooth voltage profiles. ${ }^{14}$ The phase transformation was observed in the fully charged $(\sim 4.0 \mathrm{~V})$ electrode but original R-3 m phase was completely restored at the following discharge. The isostructural compound, $\mathrm{Na}\left[\mathrm{Ni}_{1 / 3} \mathrm{Mn}_{1 / 3} \mathrm{Co}_{1 / 3}\right] \mathrm{O}_{2}$, showed reversible intercalation of $0.5 \mathrm{Na}$-ions leading to the specific capacity of $120 \mathrm{mAhg}^{-1}$ in the voltage range of 2.0 $3.75 \mathrm{~V} .{ }^{15}$ In-situ XRD revealed the sequential phase evolutions (O3, O1, P3 and P1) composed of biphasic and monophasic domains upon the Na-ions extraction associated with stair-like voltage profiles (Fig. 3(b)). In addition, Na $\left[\mathrm{Ni}_{1 / 3} \mathrm{Mn}_{1 / 3} \mathrm{Co}_{1 / 3}\right] \mathrm{O}_{2}$ is very sensitive to air and long exposure results in a non-stoichiometric $\mathrm{Na}_{\mathrm{x}}\left[\mathrm{Ni}_{1 / 3} \mathrm{Mn}_{1 / 3} \mathrm{Co}_{1 / 3}\right] \mathrm{O}_{2}$. $\mathrm{H}_{2} \mathrm{O}$ hydrated phase.

In addition to the $\mathrm{O} 3$ phase, $\mathrm{P} 2$ structured materials have been extensively studied since larger Na-ion is stable in more spacious prismatic site. Recently, $\mathrm{P} 2-\mathrm{Na}_{\mathrm{x}} \mathrm{CoO}_{2}$ has been reinvestigated by Berthelot $e t a l$. and reported to reversibly

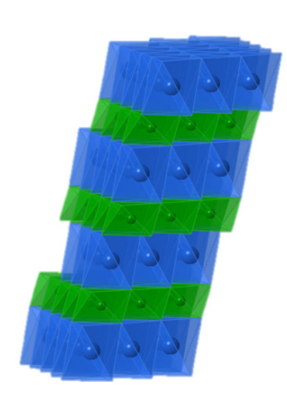

(a)

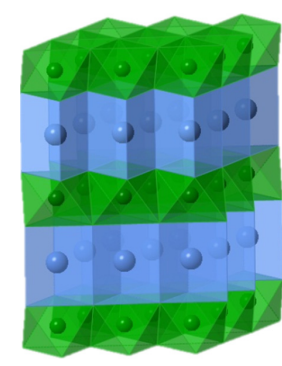

(b)

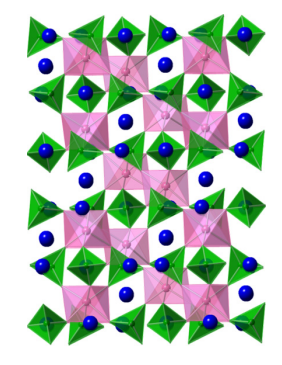

(c)

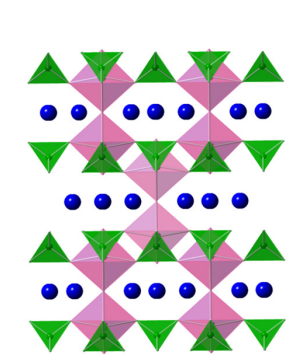

(d)

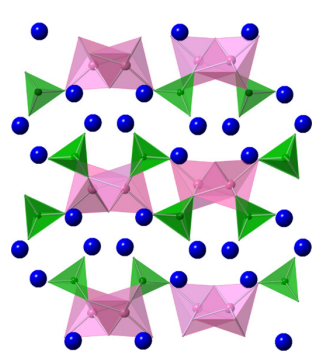

(e)

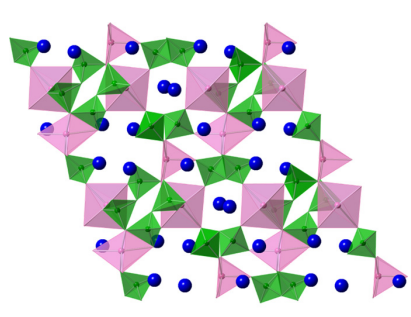

(f)

Fig. 2. Schematics of crystal structures of (a) O3, (b) P2, (c) NASICON, (d) $\mathrm{Na}_{1.5} \mathrm{VOPO}_{4} \mathrm{~F}_{0.5}$, (e) $\mathrm{Na}_{2} \mathrm{FePO}_{4} \mathrm{~F}$ and (f) $\mathrm{Na}_{2} \mathrm{FeP}_{2} \mathrm{O}_{7}$. 


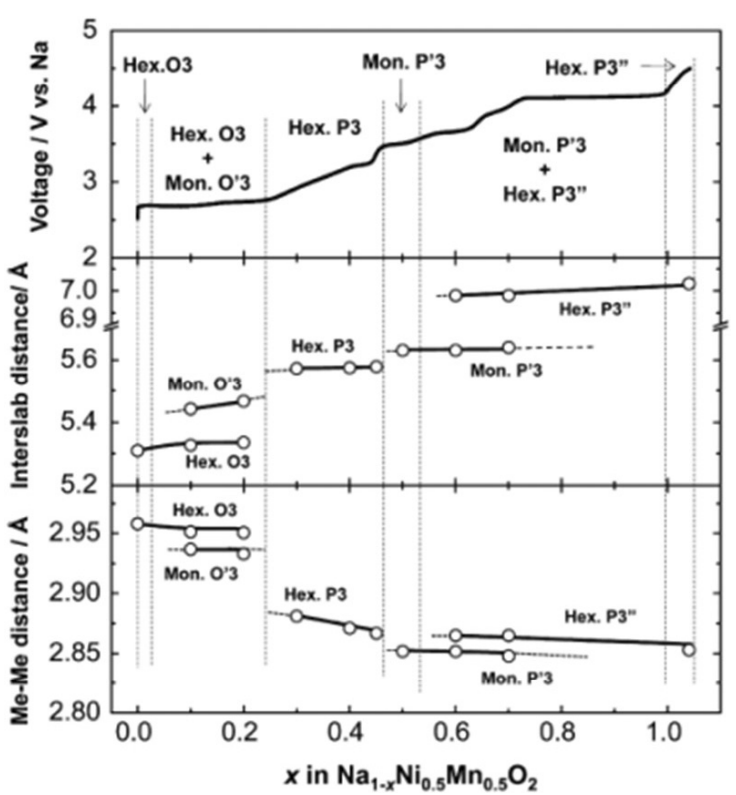

(a)

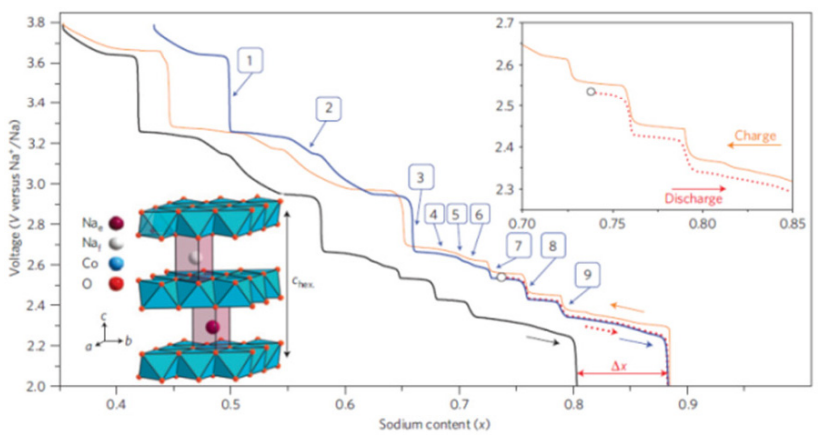

(c)

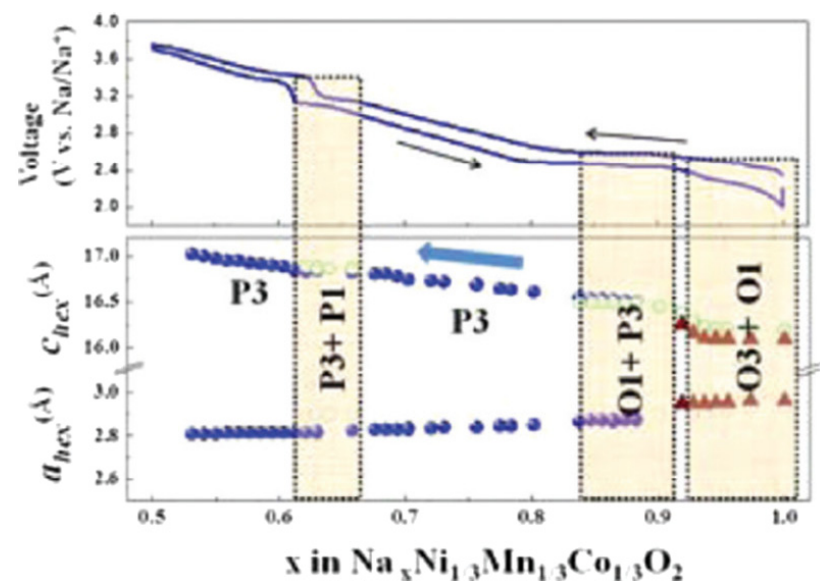

(b)

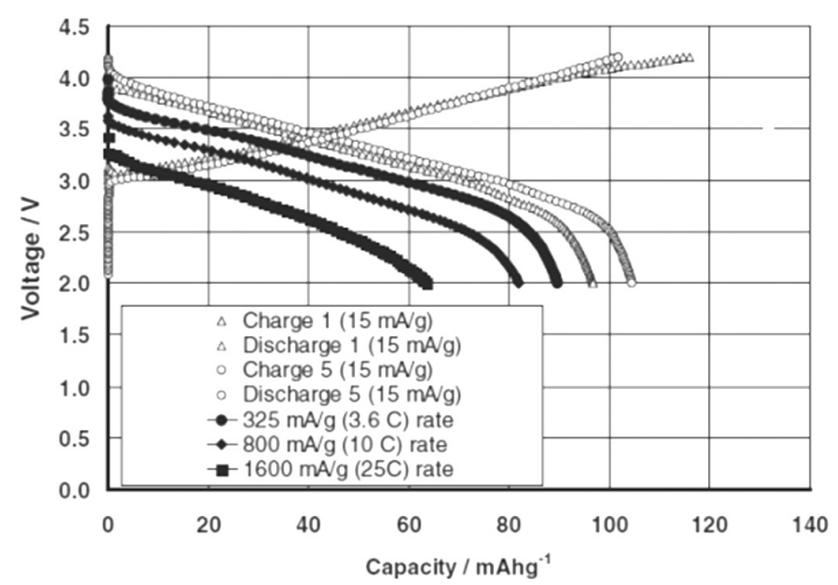

(d)

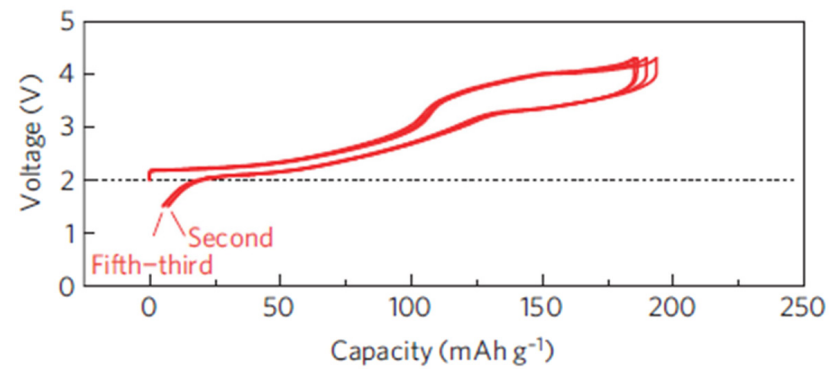

(e)

Fig. 3. The electrochemical voltage profiles of various layered oxide compounds: (a) $\mathrm{O} 3-\mathrm{NaNi}_{0.5} \mathrm{Mn}_{0.5} \mathrm{O}_{2},{ }^{12}$ (b) $\mathrm{O} 3-\mathrm{Na}\left[\mathrm{Ni}_{1 / 3} \mathrm{Mn}_{1 / 3} \mathrm{Co}_{1 / 3}\right] \mathrm{O}_{2},{ }^{15}$ (c) $\mathrm{P} 2-$ $\mathrm{Na}_{\mathrm{x}} \mathrm{CoO}_{2},{ }^{16}$ (d) $\mathrm{P} 2-\mathrm{Na}_{1.0} \mathrm{Li}_{0.2} \mathrm{Ni}_{0.25} \mathrm{Mn}_{0.75} \mathrm{O}_{2},{ }^{21}$ (e) $\mathrm{P} 2-\mathrm{Na}_{2 / 3}\left[\mathrm{Fe}_{1 / 2} \mathrm{Mn}_{1 / 2}\right] \mathrm{O}_{2} .{ }^{.2}$

operate between $0.45 \leq x \leq 0.90 .{ }^{16}$ The in-situ XRD indicated that nine single-phase domains with narrow sodium composition ranges were observed due to distinctive $\mathrm{Na}^{+}$/vacancy orderings (Fig. 3(c)). $\mathrm{P} 2-\mathrm{Na}_{\mathrm{x}} \mathrm{VO}_{2}$ was also revisited and precise phase diagram determined from electrochemical Na-ions intercalation and extraction was reported. ${ }^{17}$ Four different monophasic domains due to different $\mathrm{Na}^{+} /$vacancy ordering between $\mathrm{VO}_{2}$ slabs were evidenced 
within the $x$ range of $0.5-0.8$ leading to the superstructures. The Mn substituted $\mathrm{P} 2-\mathrm{Na}_{2 / 3}\left[\mathrm{Co}_{2 / 3} \mathrm{Mn}_{1 / 3}\right] \mathrm{O}_{2}$, where $\mathrm{Co}^{3+}$ and $\mathrm{Mn}^{4+}$ coexist, was investigated by the same group. ${ }^{18}$ Unlike its analogue, $\mathrm{P} 2-\mathrm{Na}_{2 / 3} \mathrm{CoO}_{2}, \mathrm{P} 2-\mathrm{Na}_{2 / 3}\left[\mathrm{Co}_{2 / 3} \mathrm{Mn}_{1 / 3}\right] \mathrm{O}_{2}$ displayed only one voltage step at $\mathrm{Na}_{1 / 2}\left[\mathrm{Co}_{2 / 3} \mathrm{Mn}_{1 / 3}\right] \mathrm{O}_{2}$ composition. It was speculated that the presence of disordered arrangements of $\mathrm{Co}^{3+}$ and $\mathrm{Mn}^{4+}$ in the transition metal (TM) slab might prevent the Na-ions ordering. A study by $\mathrm{Lu}$ et al. demonstrated that the $\mathrm{P} 2-\mathrm{Na}_{2 / 3}\left[\mathrm{Ni}_{1 / 3} \mathrm{Mn}_{2 / 3}\right] \mathrm{O}_{2}$ can reversibly exchange $2 / 3$ of $\mathrm{Na}$-ions in $\mathrm{Na}$ cells leading to the capacity of $160 \mathrm{mAh} \mathrm{g}^{-1}$ between $2.0-4.5 \mathrm{~V} .{ }^{19,20}$ The phase transformation of $\mathrm{P} 2$ to $\mathrm{O} 2$ at the high voltage region was evidenced by in-situ XRD and it caused the significant capacity fading and poor rate capability. However, when this material was recently revisited by Lee et al., the electrodes delivered $89 \mathrm{mAh} \mathrm{g}^{-1}$ at $\mathrm{C} / 20$ and $85 \%$ of capacity at $1 \mathrm{C}$ was obtained with excellent cycling performances by excluding the phase transformation region. ${ }^{3}$ It was revealed that the diffusivity of Na-ions in P2 structure is higher than that in the corresponding $\mathrm{O} 3$ structured $\mathrm{Li}$ compounds. $\mathrm{Li}$ substituted $\mathrm{Na}_{1.0} \mathrm{Li}_{0.2} \mathrm{Ni}_{0.25} \mathrm{Mn}_{0.75} \mathrm{O}_{2}$ was studied by Kim et al. and displayed $95-100 \mathrm{mAhg}^{-1}$ of specific capacity in the voltage range of $2.0-4.2 \mathrm{~V}$, excellent cycling and rate capabilities (Fig. 3(d)). ${ }^{21}$ It is hypothesized that substituted $\mathrm{Li}$ in TM layer improves the structural stability during the cycling, however the precise roles of substitited $\mathrm{Li}$ are not clearly undersood yet. Recently, Yabuuchi et al. reported that $\mathrm{Na}_{2 / 3}\left[\mathrm{Fe}_{1 / 2} \mathrm{Mn}_{1 / 2}\right] \mathrm{O}_{2}$ delivers the capacity of $190 \mathrm{mAh} \mathrm{g}^{-1}$ between 1.5 and $4.2 \mathrm{~V}$ (Fig. 3(e)). ${ }^{22}$ The energy density is estimated to be $520 \mathrm{mWh} \mathrm{g}^{-1}$, which is comparable to that of $\mathrm{LiFePO}_{4}\left(530 \mathrm{mWh} \mathrm{g}^{-1}\right)$. They evidenced that highly reversible phase transformation of $\mathrm{P} 2$ to $\mathrm{OP} 4$ occurring above $3.8 \mathrm{~V}$ and $\mathrm{Fe}^{3+} / \mathrm{Fe}^{4+}$ redox couple is electrochemically active in Na-ion cells. Newly designed $\mathrm{Na}_{0.83}\left[\mathrm{Li}_{0.07} \mathrm{Ni}_{0.31} \mathrm{Mn}_{0.62}\right] \mathrm{O}_{2}$ material is being investigated by the authors and showed $130 \mathrm{mAh} \mathrm{g}^{-1}$ of reversible capacity (Fig. 1). This study is now in progress.

In summary, the electrochemical performances of $\mathrm{O} 3$ and $\mathrm{P} 2$ type $\mathrm{Na}_{\mathrm{x}} \mathrm{MO}_{2}$ layered compounds have been considerably improved showing the average energy density of $300-520 \mathrm{mWh} \mathrm{g}^{-1}$. The major challenges are the phase transformations by layer shifting and $\mathrm{Na}^{+}$/vacancy ordering which cause poor reversibility and the stair-like voltage profiles. Recent studies have shown that the substitution of different transition metals or $\mathrm{Li}$, and confinement of operating voltage window can inhibit the $\mathrm{Na}$ ordering phenomena and layer shifting indicating smooth voltage profiles. However the way to delay or suppress the phase transformation in high voltage region remains as a major challenge to obtain higher energy density in Na-ion batteries. In addition, hydrated phase of sodium layered compounds can be readily formed by long exposure in air; therefore the atmosphere needs to be precisely controlled in handling $\mathrm{Na}_{\mathrm{x}} \mathrm{MO}_{2}$ compounds.

\section{Polyanion Compounds}

Recently, polyanion compounds have attracted considerable attention for Na-ion batteries. Various crystal structures are demonstrated to be able to accommodate Na-ions due to their open channels. In polyanion compounds, tetrahedral polyanion structure units $\left(\mathrm{XO}_{4}\right)^{\mathrm{n}-}(\mathrm{X}=\mathrm{P}$ or $\mathrm{S})$ are combined with $\mathrm{MO}_{6}(\mathrm{M}=$ transition metal) polyhedra. Due to the strong covalent bonding in $\left(\mathrm{XO}_{4}\right)^{\mathrm{n}-}$, polyanion cathode materials usually possess high thermal stability, which make them more suitable for large-scale energy applications. Moreover, since the operation voltage is influenced by local environment of polyanions, the voltage of a specific redox couple can be tuned for this type of materials.

Compounds based on the 3D structure of NASICON are extensively studied for their structural stability and fast ion conduction, initially as solid electrolytes. ${ }^{23-25}$ and more recently as insertion materials. ${ }^{26-33}$ The general formula is $\mathrm{A}_{\mathrm{x}} \mathrm{MM}^{\prime}\left(\mathrm{XO}_{4}\right)_{3}$, in which corner-shared $\mathrm{MO}_{6}$ (or $\mathrm{M}^{\prime} \mathrm{O}_{6}$ ) and $\mathrm{XO}_{4}$ polyhedra form a framework with large $\mathrm{Na}$ diffusion channels (Fig. 2(c)). ${ }^{34}$ In 1987 and 1988, Delmas et al. demonstrated that NASICON-type compounds, $\mathrm{NaTi}_{2}\left(\mathrm{PO}_{4}\right)_{3}$, can be electrochemically active with $\mathrm{Na}$ in a reversible manner. ${ }^{26,27}$ Later $\mathrm{NaNbFe}\left(\mathrm{PO}_{4}\right)_{3}, \mathrm{Na} 2 \mathrm{TiFe}\left(\mathrm{PO}_{4}\right)_{3}$ and $\mathrm{Na}_{2} \mathrm{TiCr}\left(\mathrm{PO}_{4}\right)_{3}$ were explored. ${ }^{29-31}$ Since then, most studies of this family of compounds were focused on Li-ion batteries, because the cell performance was generally poor in $\mathrm{Na}$-ion batteries. Sodium intercalation in $\mathrm{Na}_{3} \mathrm{~V}_{2}\left(\mathrm{PO}_{4}\right)_{3}$ was first synthesized in 2002 by Yamaki et al. ${ }^{35}$ The existence of two voltage plateau at 1.6 and $3.4 \mathrm{~V}$ vs. $\mathrm{Na} / \mathrm{Na}^{+}$allowed using this phase not only as cathode but also anode in a symmetric cell (Fig. 4(a)). However, the cycling stability of this symmetric cell was relatively poor. ${ }^{32}$ Recently, several methods have been utilized to coat carbon on $\mathrm{Na}_{3} \mathrm{~V}_{2}\left(\mathrm{PO}_{4}\right)_{3}$ to improve the battery performance. ${ }^{33,36}$ Among all, Balaya et al. reported the excellent cycling stability and superior rate capability, ${ }^{37}$ which was attributed to facile sodium ion diffusion in the nano-sized particles embedded in a conductive matrix.

Unlike the olivine $\mathrm{LiFePO}_{4},{ }^{38,39}$ the sodium analogue, $\mathrm{NaFePO}_{4}$, was not extensively investigated. The olivine $\mathrm{NaFePO}_{4}$ can be obtained by extracting Li-ions out of $\mathrm{LiFePO}_{4}$ and subsequently inserting Na-ions into $\mathrm{FePO}_{4} \cdot{ }^{40}$ Upon Na-ion extraction, two different plateaus were clearly observed in the voltage-composition curve (Fig. 4(b)), resulted from two successive first-order transitions concomitant with the formation of an intermediate $\mathrm{Na}_{0.7} \mathrm{FePO}_{4}{ }^{41,42}$ On the other hand, only one plateau is observed upon 


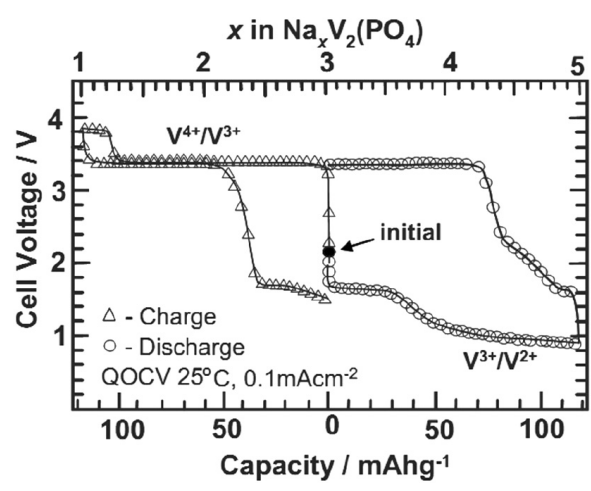

(a)

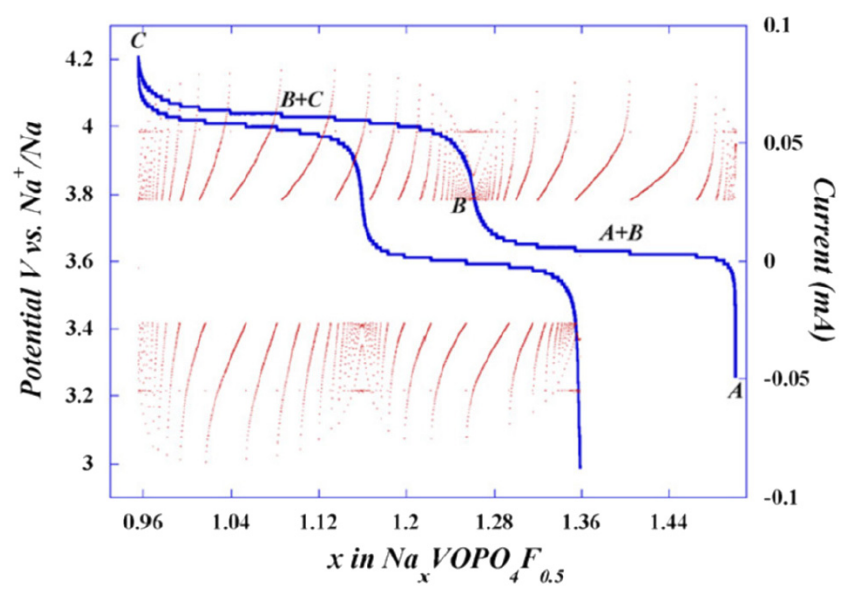

(c)

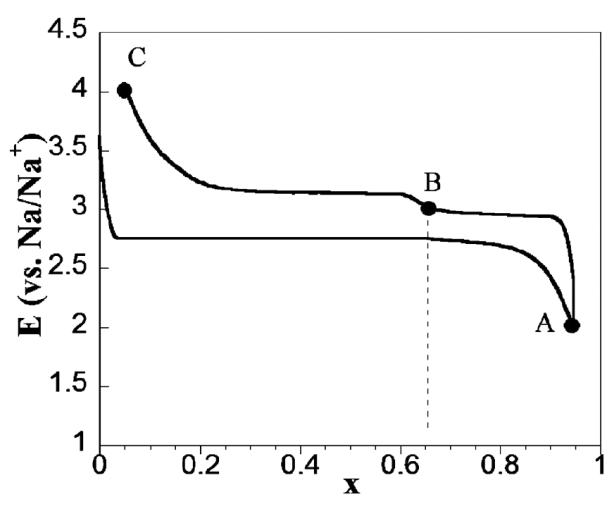

(b)

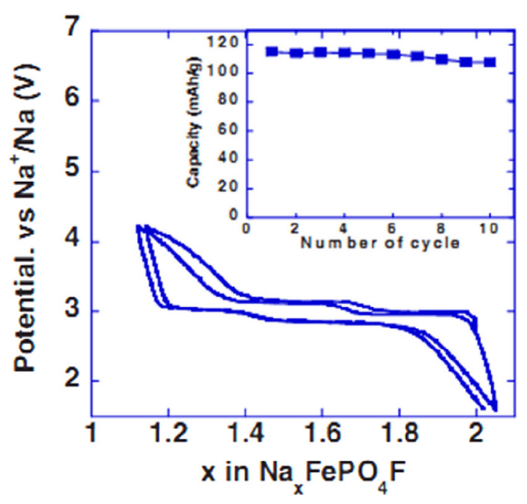

(d)

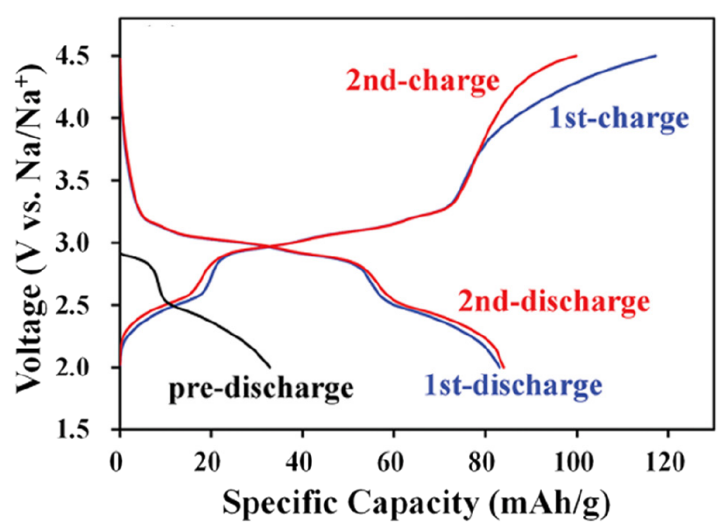

(e)

Fig. 4. The electrochemical voltage profiles of various polyanion compounds: (a) $\mathrm{Na}_{3} \mathrm{~V}_{2}\left(\mathrm{PO}_{4}\right)_{3},{ }^{32}$ (b) $\mathrm{NaFePO}_{4},{ }^{41}$ (c) $\mathrm{Na}_{1.5} \mathrm{VOPO}_{4} \mathrm{~F}_{0.5},{ }^{49}$ (d) $\mathrm{Na}_{2} \mathrm{FePO}_{4} \mathrm{~F}^{51}$ and (e) $\mathrm{Na}_{2} \mathrm{FeP}_{2} \mathrm{O}_{7} .{ }^{54}$

discharge, indicating that the charge and discharge process might go through different reaction paths. Recently, Cabanas et al. demonstrated that the $\mathrm{Na}$ insertion into $\mathrm{FePO}_{4}$ occurred via an intermediate phase which buffers the internal stresses. ${ }^{43}$ Besides the pure iron olivine, the $\mathrm{NaFe}_{0.5} \mathrm{Mn}_{0.5} \mathrm{PO}_{4}$ was synthesized by a molten salt reaction. ${ }^{44}$ Compared with $\mathrm{NaFePO}_{4}$, a sloping profile over the entire voltage range was displayed in Na-ion batteries. The origin of this solid solution behavior was not clarified.

In the quest for new cathode materials, various structures with different polyanion groups are demonstrated to be promising candidates. The family of sodium vanadium fluorophosphates, $\mathrm{NaVPO}_{4} \mathrm{~F}^{45} \quad \mathrm{Na}_{3} \mathrm{~V}_{2}\left(\mathrm{PO}_{4}\right)_{2} \mathrm{~F}_{3},{ }^{46-48}$ and $\mathrm{Na}_{1.5} \mathrm{VOPO}_{4} \mathrm{~F}_{0.5},{ }^{49}$ have attracted interests due to high 
potential of the $\mathrm{V}^{3+} / \mathrm{V}^{4+}$ redox reaction. Though the electrochemical activities of $\mathrm{NaVPO}_{4} \mathrm{~F}$ have been demonstrated in Na-ion batteries, ${ }^{45}$ no long-term electrochemical tests have been reported so far. $\mathrm{Na}_{3} \mathrm{~V}_{2}\left(\mathrm{PO}_{4}\right)_{2} \mathrm{~F}_{3}$ was first reported by Meins et al. $^{46}$ and its good cyclability was achieved recently. ${ }^{48}$ Concerning $\mathrm{Na}_{1.5} \mathrm{VOPO}_{4} \mathrm{~F}_{0.5}$, Sauvage et al. claimed that a reversible capacity of $87 \mathrm{mAh} \mathrm{g}^{-1}$ was shown by galvanostatic cycling of the material at $\mathrm{C} / 20$ (Fig. 4(c)). ${ }^{49}$ The compound was comprised of layers of alternating $\left[\mathrm{VO}_{5} \mathrm{~F}\right]$ octahedral and $\left[\mathrm{PO}_{4}\right]$ tetrahedral sharing $\mathrm{O}$ vertices (Fig. 2(d)). Moreover, $\mathrm{Na}_{2} \mathrm{FePO}_{4} \mathrm{~F}$ was first studied by Nazar et al., in which two-dimensional iron phosphate sheets host two Na-ions (Fig. 2(e))..$^{50}$ Later, the ionothermal synthesis was applied to prepare this compound, so that the morphology could be controlled. ${ }^{51}$ In Fig. 4(d), a reversible two-plateau behavior was displayed in the electrochemical profiles vs. Na metal, and the discharge capacity was over $100 \mathrm{mAh} \mathrm{g}^{-1}$ during 10 cycles. With regard to pyrophosphate, a variety of Na-based pyrophosphates are investigated ${ }^{52-54}$ While these pyrophosphate materials adopt different crystal structures depending on transition metals, most of them contain open frameworks that could facilitate efficient diffusion of Na-ions. Recently, a new version of Fe-based pyrophosphate, $\mathrm{Na}_{2} \mathrm{FeP}_{2} \mathrm{O}_{7}$, was firstly reported as the cathode materials, (Fig. 2(f))..$^{54}$ This material delivered $90 \mathrm{mAhg}^{-1}$ of reversible capacity with two distinct plateaus at $2.5 \mathrm{~V}$ and $3.1 \mathrm{~V}$ respectively, as shown in Fig. 4(e). Excellent thermal stability was also observed up to $500^{\circ} \mathrm{C}$, indicating that the $\mathrm{Na}_{2} \mathrm{FeP}_{2} \mathrm{O}_{7}$ could be a promising candidate for positive electrode material in Na-ion batteries. In addition to phosphate-based compounds, sodium transition metal fluorosulphates, $\mathrm{NaMSO}_{4} \mathrm{~F}$, exhibit high $\mathrm{Na}$-ion ionic conductivity and have been tested for the electrochemical activities in Na-ion battery. In $\mathrm{NaFeSO}_{4} \mathrm{~F}$, Na-ions reside in the spacious tunnels constructed by corner-shared $\mathrm{FeSO}_{4} \mathrm{~F}$ frameworks. ${ }^{55,56}$ These materials were demonstrated to work reversibly in hybrid Li-ion batteries; however no decent reversibility has obtained in Na-ion batteries. ${ }^{57,58}$

In summary, the polyanion compounds have provided a wide variety of novel materials with the possibility to design their compositions and structures. Their robust framework and good thermal stability make them promising candidates for the cathodes materials in Na-ion batteries. With the dramatic improvement in cell-design and electrode engineering, the intrinsic low electronic conductivity of polyanion compounds has been improved significantly. However, it is still in the early stages to develop polyanion compounds as matured electrodes, and more research is required in order to clarify their structural characteristics and $\mathrm{Na}$ insertion-extraction phase transformation mechanisms.

\section{Conclusion}

It is fascinating and encouraging to see that significant progress has been achieved through new synthesis methods and composition design for sodium intercalation compounds. However, it would be worth to note that Na-ion batteries still exhibit lower energy density than Li counterparts largely arising from cathode materials. Such drawbacks may confine their applications to large-scale stationary energy storages. Besides the cathode materials, more efforts must be made to search for better negative electrode materials to make the Na-ion batteries more economic and sustain longer life. ${ }^{59}$ For more details on the synthesis and electrochemistry of the sodium intercalation compounds the readers can refer to a few excellent reviews preceded this one. ${ }^{34,60,61}$

\section{Acknowledgments}

The authors acknowledge the funding support by the USA National Science Foundation under Award Number 1057170.

\section{References}

1. J. L. Sudworth, J. Power Sources 100, 149 (2001).

2. S. P. Ong et al., Energy Environ. Sci. 4, 3680 (2011).

3. D. H. Lee et al., Phys. Chem. Chem. Phys. doi: 10.1039/ C2CP44467D.

4. C. Delmas et al., Physica B \& C 99, 81 (1980).

5. C. Delmas et al., J. Solid State Chem. 13, 165 (1975).

6. C. Fouassier et al., Mater. Res. Bull. 10, 443 (1975).

7. C. Delmas et al., Solid State Ionics 3, 165 (1981).

8. J. J. Braconnier et al., Mater. Res. Bull. 17, 993 (1982).

9. A. Mendiboure et al., J. Solid State Chem. 57, 323 (1985).

10. Y. Takeda et al., Mater. Res. Bull. 29, 659 (1994).

11. S. Komaba et al., Electrochem. Commun. 12, 355 (2010).

12. S. Komaba et al., ECS Trans. 16, 43 (2009).

13. S. Komaba et al., Inorg. Chem. 51, 6211 (2012).

14. D. Kim et al., Electrochem. Commun. 18, 66 (2012).

15. M. Sathiya et al., Chem. Mater. 24, 1846 (2012).

16. R. Berthelot et al., Nat. Mater. 10, 74 (2011).

17. M. Guignard et al., Nat. Mater. 12, 74 (2013).

18. D. Carlier et al., Dalton Trans. 40, 9306 (2011).

19. Z. H. Lu and J. R. Dahn, J. Electrochem. Soc. 148, A710 (2001).

20. Z. H. Lu and J. R. Dahn, J. Electrochem. Soc. 148, A1225 (2001).

21. D. Kim et al., Adv. Energy Mater. 1, 333 (2011).

22. N. Yabuuchi et al., Nat. Mater. 11, 512 (2012).

23. S. Yao et al., Chem. Lett. 20, 2069 (1991).

24. U. Von Alpen et al., Mater. Res. Bull. 14, 1317 (1979).

25. P. Knauth, Solid State Ionics 180, 911 (2009).

26. C. Delmas et al., Mater. Res. Bull. 22, 631 (1987).

27. C. Delmas et al., Solid State Ionics 28, 419 (1988).

28. J. Gopalakrishnan and K. K. Rangan, Chem. Mater. 4, 745 (1992).

29. O. Tillement et al., Solid State Ionics 53, 391 (1992). 
30. K. S. Nanjundaswamy et al., Solid State Ionics 92, 1 (1996).

31. S. Patoux et al., Chem. Mater. 15, 2084 (2003).

32. L. S. Plashnitsa et al., J. Electrochem. Soc. 157, A536 (2010).

33. Z. L. Jian et al., Electrochem. Commun. 14, 86 (2012).

34. S. W. Kim et al., Adv. Energy Mater. 2, 710 (2012).

35. Y. Uebou et al., The Rep. Inst. Adv. Mater. Study 16, 1 (2002).

36. J. Kang et al., J. Mater. Chem. 22, 20857 (2012).

37. K. Saravanan et al., Adv. Energy Mater. doi: 10.1002/ aenm.201200803.

38. Z. L. Gong and Y. Yang, Energy Environ. Sci. 4, 3223 (2011).

39. A. K. Padhi et al., J. Electrochem. Soc. 144, 1188 (1997).

40. T. Shiratsuchi et al., J. Power Sources 159, 268 (2006).

41. P. Moreau et al., Chem. Mater. 22, 4126 (2010).

42. K. Zaghib et al., J. Power Sources 196, 9612 (2011).

43. M. Casas-Cabanas et al., J. Mater. Chem. 22, 17421 (2012).

44. K. T. Lee et al., Chem. Mater. 23, 3593 (2011).

45. J. Barker et al., Electrochem. Solid-State Lett. 6, A1 (2003).

46. J. M. Le Meins et al., J. Solid State Chem. 148, 260 (1999).
47. J. Barker et al., Electrochem. Solid-State Lett. 9, A190 (2006).

48. R. A. Shakoor et al., J. Mater. Chem. 22, 20535 (2012).

49. F. Sauvage et al., Solid State Sci. 8, 1215 (2006).

50. B. L. Ellis et al., Nat. Mater. 6, 749 (2007).

51. N. Recham et al., J. Electrochem. Soc. 156, A993 (2009).

52. Y. Uebou et al., Electrochemistry 71, 308 (2003).

53. P. Barpanda et al., Adv. Energy Mater. 2, 841 (2012).

54. H. Kim et al., Adv. Funct. Mater. doi: 10.1002/adfm. 201201589.

55. M. Ati et al., Chem. Mater. 22, 4062 (2010).

56. R. Tripathi et al., Angew. Chem. Int. Ed. 49, 8738 (2010).

57. B. L. Ellis et al., Chem. Mater. 23, 5138 (2011).

58. R. Tripathi et al., Chem. Mater. 23, 2278 (2011).

59. P. Senguttuvan et al., Chem. Mater. 23, 4109 (2011).

60. V. Palomares et al., Energy Environ. Sci. 5, 5884 (2012).

61. M. D. Slater et al., Adv. Funct. Mater. doi: 10.1002/adfm. 201200691. 